\title{
Evaluating Iris Yellow Spot Disease Incidence and Severity in Onion Germplasm of Varying Leaf Characteristics
}

\author{
Christopher S. Cramer ${ }^{1,3}$, Neel Kamal ${ }^{2}$, and Narinder Singh ${ }^{2}$ \\ Department of Plant and Environmental Sciences, New Mexico State \\ University, Box 30003, MSC 3Q, Las Cruces, NM 88003-8003
}

Additional index words. Allium cepa, Iris yellow spot virus, IYSV, Thrips tabaci

\begin{abstract}
Iris yellow spot (IYS) disease, caused by Iris yellow spot virus (IYSV), results in irregular and diamond-shaped, chlorotic, and necrotic lesions on the leaves and seedstalks of onions (Allium cepa $\mathbf{L}$.). These lesions reduce leaf photosynthetic area and ultimately reduce onion bulb size and yield from larger bulb classes. IYSV is vectored by onion thrips (Thrips tabaci $\mathbf{L}$.) that are difficult to control under certain environmental conditions. Currently, no onion cultivar is resistant to the disease symptoms, virus, and/or thrips. Twenty-one cultivars and 17 germplasm lines were evaluated in the field for IYS disease severity and thrips densities at multiple times during the season as well as leaf color, waxiness, and axil openness of these entries. Plants were grown under conditions that favored thrips populations (high temperatures, low moisture, and no insecticidal spray applications), IYSV presence and distribution, and IYS development. Plants of New Mexico State University (NMSU) 07-10-1 had fewer thrips than several entries later in the season in both 2009 and 2010. Several entries exhibited a lower number of thrips per plant early or later in the season; however, these results were not consistent across years and were not associated with a particular foliage characteristic. Lighter leaf color and/or a lesser amount of epicuticular wax did not always result in the fewest number of thrips per plant as has been reported in the literature. Plants of NMSU 09-58 tended to exhibit fewer and less severe IYS symptoms early in the season as compared with plants of other entries.
\end{abstract}

IYS disease, caused by IYSV (family Bunyaviridae, genus Tospovirus), has been found in most onion producing states in the United States (Bag et al., 2009; Creamer et al., 2004; Crowe and Pappu, 2005; du Toit et al., 2004a; Gent et al., 2006; Hall et al., 1993; Hoepting et al., 2007; Miller et al., 2006; Mullis et al., 2004; Pappu and Matheron, 2008; Poole et al., 2007; Schwartz et al., 2002). The irregular diamond-shaped, straw-colored lesions indicative of IYS are found on either leaves or seedstalks reduce leaf photosynthetic area. This reduction decreases onion bulb size and yield of larger bulb classes or causes premature seedstalk lodging that in turn reduces seed yield (du Toit et al., 2004b; Gent et al., 2004). IYSV is transmitted

\footnotetext{
Received for publication 13 Jan. 2017. Accepted for publication $27 \mathrm{Feb} .2017$.

This research was funded in part by the USDA-CSREES Specialty Crop Research Initiative, grant award 2008-51180-04875, the New Mexico Dry Onion Commission, and the New Mexico Agricultural Experiment Station.

We wish to thank American Takii, Crookham Company, DP Seeds, Lockhart Seeds Inc., Nunhems, and Monsanto Vegetable Seeds for the donation of onion seed.

${ }^{1}$ Professor of Horticulture

${ }^{2}$ Graduate Student

${ }^{3}$ Corresponding author. E-mail: cscramer@nmsu. edu.
}

only by onion thrips (T. tabaci) (Kritzman et al., 2001; Nagata et al., 1999) that acquire the virus during their larval stage and transmit the virus for their entire life. Control of IYS requires an integrated approach including control of the vector, cultural practices, and genetic resistance/tolerance. Control of thrips has relied primarily on insecticides with varying success depending on the pesticide chemistry, thrips population levels, and environmental conditions (Gill et al., 2015). However, thrips resistance to several insecticides has developed in several different onion production areas (MacIntyre Allen et al., 2005; Martin et al., 2003; Shelton et al., 2003). Cultural practices used to control IYS involve minimizing plant stress, but that becomes difficult during hot and dry climactic conditions found in many onion growing regions. High levels of plant stress may cause the symptoms of IYS to become worse. The development of cultivars that are resistant to thrips and/or IYSV would be advantageous for long-term control of this pest complex.

The development of onion cultivars that are resistant to onion thrips has focused primarily on onion leaf color and amount of epicuticular wax as it relates to thrips feeding nonpreference. As suggested by some studies, thrips prefer blue-colored foliage to light green and green-colored foliage [(Czencz, 1987; Kirk, 1984; Lu, 1990) cited in Gent et al., 2006]. Often associated with leaf color is the amount of epicuticular wax found on onion leaves. Plants with blue-colored foliage tend to have a higher amount of epicuticular leaf wax. Thrips appear to prefer onions with bluish colored foliage and higher amounts of epicuticular wax. Diaz-Montano et al. (2012a) observed that cultivars with bluish colored foliage, often associated with higher wax levels, had significantly higher number of thrips larvae as compared with cultivars with lighter colored foliage. Normal waxy onions possess copious amounts of epicuticular waxes (Damon et al., 2014) that build up on leaf surfaces and allow thrips to adhere to the plant and incite damage. Glossy foliage accumulates only sparse amounts of epicuticular waxes, appears lighter green in color, slows the growth of thrips populations, and experiences less damage from thrips feeding (Alimousavi et al., 2007; Damon et al., 2014; Jones et al., 1934; Molenaar, 1984; Mote and Sonone, 1977; Pawar et al., 1975). Some heirloom cultivars of onion (such as 'Colorado no. 6' and many 'Sweet Spanish' cultivars) are "semi-glossy" (Damon et al., 2014), meaning that the plants may accumulate an intermediate amount of epicuticular waxes relative to glossy and waxy plants. In addition, the amount of hentriacontanone-16 wax relative to the other epicuticular waxes may influence the amount of total wax present on plant leaves (Damon et al., 2014). Cultivars with these leaf characteristics may be desirable for their reduced thrips numbers and possible reduced IYSV transmission and IYS disease development. Another trait that can influence thrips feeding preference on onion plants could be leaf axil pattern because it was thought that an open leaf axil pattern would be less attractive to thrips as they are thigmotactic (i.e., prefer to feed in tight spaces), and an open leaf axil pattern would provide them less protection from predators and environment than a tight leaf axil pattern. Conversely, Jones et al. (1934) suggested that a tight leaf axil might be involved in thrips resistance by preventing them access to the leaf axil.

Although numerous evaluations have been conducted, no onion cultivar or breeding line has been found to be highly resistant to IYS (Boateng et al., 2014; Cramer et al., 2012, 2014; Diaz-Montano et al., 2012a, 2012b; du Toit et al., 2004b; Gent et al., 2004, 2006; Mohseni-Moghadam et al., 2011; Multani et al., 2009; Schwartz et al., 2005; Shock et al., 2008). Shock et al. (2008) found that 'Joaquin', 'Charismatic', and 'Affirmed' expressed some of the lowest IYS ratings over a 2-year period. Multani et al. (2009) observed that among 18 winter-sown entries, NMSU 03-52-1, NMSU 04-41, NMSU 0444-1, and 'NuMex Jose Fernandez' exhibited the fewest IYS symptoms. Among 17 onion entries evaluated for IYSV infection in a field trial in New York, NMSU 03-52-1 was ranked last with the least number of infected plants (Diaz-Montano et al., 2012b). NMSU 05-33-1 exhibited a delayed symptom expression when compared with 12 other entries (Mohseni-Moghadam et al., 2011). In 
another study, 'Cometa' and NMSU 05-35-1 exhibited a delay in symptom expression and lower IYSV levels relative to 20 other entries (Cramer et al., 2012). Plants of PI accessions, 239633 and 546192, exhibited less severe IYS disease symptoms than plants of other accessions (Cramer et al., 2014). In addition, plants of accessions 258956, 264320, 546140, and 546188 exhibited less disease symptoms than other accessions when evaluated in Colorado (Boateng et al., 2014). Selection of plants with less severe IYS symptoms occurred in both the IYS evaluation studies in New Mexico (Cramer et al., 2014) and Colorado (Boateng et al., 2014). The objective of this research was to evaluate onion germplasm that may have expressed reduced IYS disease symptoms in previous screenings in the hopes of developing disease-resistant populations. Additional traits also were noted such as foliage color, glossiness, degree of leaf axil openness, and number of thrips per plant.

\section{Materials and Methods}

Eighteen commercial cultivars, three NMSU cultivars, and 17 NMSU experimental breeding lines were evaluated for IYS disease symptom severity and incidence, thrips number per plant, and leaf color and glossiness when they were grown under field conditions during the 2009, 2010, and/or 2011 growing seasons (Tables 1 and 2). Entries were divided into two groups based on when the entries were evaluated. The first group was evaluated in 2009 and 2010. Additional entries were evaluated in 2010 and 2011 and placed into a second group. Entries were commercially acceptable intermediateday and long-day type cultivars or breeding lines from different market classes (i.e., yellow, white, and red) and foliage colors (green, blue-green, and blue leaf color) with varying levels of resistance to IYSV and tolerance to thrips feeding injury and/or lower preference for thrips. For some of the NMSU breeding lines and cultivars, earlier generations had been previously evaluated (Mohseni-Moghadam et al., 2011) and exhibited lower IYS disease incidence and severity. Seed of these breeding lines is available on request. Entries were evaluated with the additional intent of making selections within each entry of individual plants expressing fewer disease symptoms. Seeds of entries were sown directly into the field at the Leyendecker Plant Science Research Center, $2.5 \mathrm{~km}$ south of Las Cruces, NM, on 23 Mar. 2009, 23 Feb. 2010, and 23 Feb. 2011. Plots consisted of a single planted, raised bed $3 \mathrm{~m}$ in length and $0.5 \mathrm{~m}$ in width, with two equally spaced planted rows. A $0.6 \mathrm{~m}$ alley was placed between plots on the same bed and beds were $1 \mathrm{~m}$ apart (center to center). Entries were arranged in a randomized complete block design with three replications. Seedlings were thinned in late April to early May in each year to $10 \mathrm{~cm}$ between two adjacent plants within the row.
To ensure that all plants in the test plots had an equal chance to become infected with IYSV, onion bulbs carrying viruliferous thrips from the previous year IYS evaluation studies were brought to the field and the field layout was designed so that IYSV would be spread naturally throughout the field by onion thrips. The field design was the same as described by Cramer et al. (2014). The presence of IYSV in representative bulbs was confirmed using enzyme-linked immunosorbent assay and reverse transcription polymerase chain reaction (Mohseni-Moghadam et al., 2011). Onion plants were grown using standard cultural practices for onion production in southern New Mexico (Walker et al., 2009), except that chemical sprays were not applied for reducing onion thrips levels.

At 12, 16, and 20 weeks in 2009 and 2010 and 13, 17, and 21 weeks in 2011 postplanting, 10 plants were arbitrarily selected from each plot and the numbers of thrips (adults and larvae) were counted on each plant. At 16 weeks in 2009 and 2010 and 17 weeks in 2011, plants in a plot were evaluated for leaf color on scale of 1 to 4 , where $1=$ light green foliage, 2 = dark green, 3 = blue green, and $4=$ blue. At the same time, plants in a plot were evaluated for the visible amount of epicuticular wax on the leaf on a scale of 1 to 4 , where 1 = glossy (no wax present), 2 = semiglossy (an intermediate amount of wax) (Damon et al., 2014), 3 = light wax, and $4=$ waxy. At 16 weeks in 2009 and 2010 only, plants in the plot were evaluated for leaf axil pattern on a scale of 1 to 4 , where $1=$ very open and $4=$ tight. At 16 and 20 weeks in 2009 and 2010 and 17, 19, and 21 weeks in 2011, 10 plants were arbitrarily selected from each plot and were rated for IYS disease severity on a scale of 0 to 4 , where $0=$ no symptoms, $1=1$ to 2 small lesions per leaf, $2=>2$ medium-sized lesions per leaf, $3=$ lesions coalescing on more than $25 \%$ of the leaf, and $4=$ more than $50 \%$ leaf death.

When more than $80 \%$ of the plants had matured (as indicated by lodging of the foliage), all bulbs from the plot were harvested. From within a plot, plants that exhibited fewer IYS foliar symptoms on maturing foliage were selected and kept separate from other bulbs harvested from the plot. Leaves and roots from the harvested bulbs were removed and bulbs were stored. Bulbs, selected for reduced symptom expression, were saved for seed production to occur in the following year.

Plots that possessed five plants or less were not used in any statistical analysis. If an entry only had one replication of data, the entry was not included in any analysis for that year. Plot means were calculated for thrips number per plant and IYS severity rating at each observation date using the "Proc Means" statement in SAS (SAS 9.2; SAS Institute Inc., Cary, NC). Entry means for leaf color, waxiness, and axil pattern rating, thrips number per plant, and IYS severity rating were calculated. Entry differences and $P$ value were determined using the "Proc
GLM" statement in SAS and Fisher's least significant difference mean separation test was performed. Entries in Trial I (2009 and 2010) were analyzed together, whereas those entries in Trial II (2010 and 2011) were analyzed together. 'Rumba' and 'Vaquero' were susceptible checks in the study and tested in all 3 years.

\section{Results and Discussion}

At the first IYS disease severity rating in 2009 and 2011, there was no difference in severity among entries (Tables 1 and 2). In 2010, plants of 'NuMex Centric' exhibited less severe disease symptoms than plants of 18 other entries at 16 weeks (Table 1 ). The disease incidence at 16 weeks for 'NuMex Centric' was $66.7 \%$ that was lower than most other entries (Table 1). Since several plants within the plot did not exhibit disease symptoms as observed by a lower disease incidence, this could be the reason for low disease severity of 'NuMex Centric'. This difference in disease severity and incidence was not likely a result of reduced thrips number or certain leaf characteristics because plants of 'NuMex Centric' exhibited a comparable number of thrips at 12 and 16 weeks as plants of entries that exhibited a greater disease severity and incidence (e.g., 'Colorado no. 6', 'Golden Spike', NMSU 07-11-1, NMSU 07-32-1, NMSU 07-56-1, NMSU 07-57-2, 'NuMex Snowball', 'Polar', 'Renegade', 'Rumba', 'Sterling', T 433, and 'Vaquero') (Table 1). Plant leaves of 'NuMex Centric' were rated as light green in color (1.0) and having less leaf wax (2.3) (Table 1). These ratings were similar to other entries (e.g., 'Colorado no. 6', 'Golden Spike', NMSU 07-11-1, NMSU 07-32-1, NMSU 07-56-1, NMSU 07-57-2, 'NuMex Snowball', 'Polar', 'Renegade', 'Sterling', T 433, and 'Vaquero') that expressed greater disease severity and incidence at the same period (Table 1). Four weeks later in 2010, nonsymptomatic plants developed disease and all plants of 'NuMex Centric' exhibited a disease severity comparable to other entries (Table 1). In 2009, when disease severity and incidence was greater at 16 weeks for all entries as compared with 2010, plants of 'NuMex Centric' were similar to plants of other entries for disease severity and incidence (Table 1).

In Trial II, plants of 'Rumba' exhibited more severe disease symptoms at 12 weeks in 2010 than plants of several other entries (Table 2). This difference was not likely due to thrips number per plant or certain leaf characteristics as plants of 'Rumba' exhibited a comparable number of thrips at 12 and 16 weeks and were rated similarly for leaf color and amount of visible leaf wax at 16 weeks as plants of entries that exhibited less severe disease symptoms (e.g., 'Early Red Burger', 'Italian Red Torpedo', 'Red Torpedo', 'Stockton Early Red', and 'Stockton Red') (Table 2). However, by 16 weeks, plants of 'Rumba' exhibited a similar disease severity as plants of other entries except for 
Table 1. Iris yellow spot (IYS) disease severity rating and incidence, number of onion thrips per plant, leaf color, glossiness, and axil openness ratings for Trial I entries measured several times throughout the 2009 and 2010 growing seasons at the Leyendecker Plant Science Research Center in Las Cruces, NM.

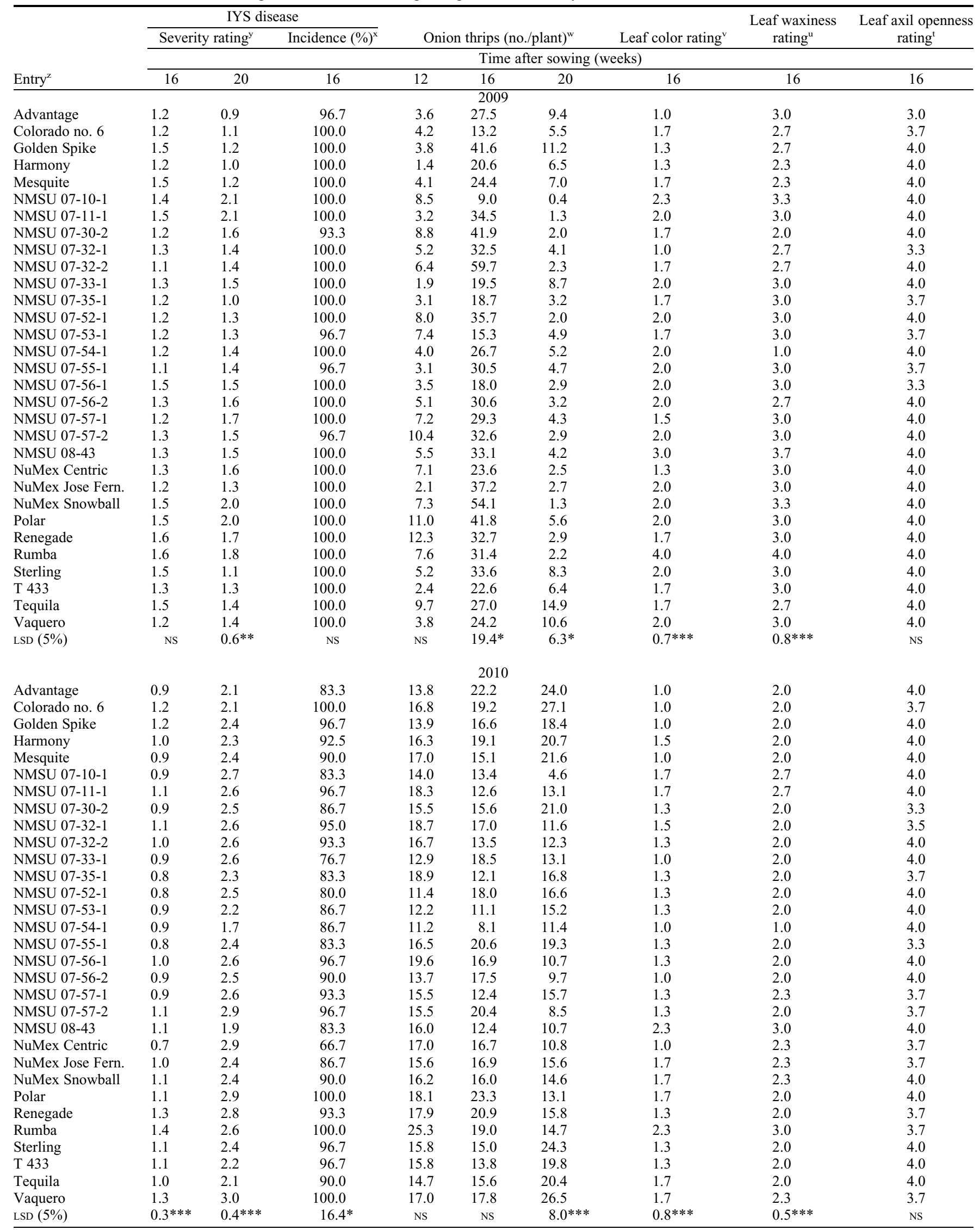


Table 1. (Continued) Iris yellow spot (IYS) disease severity rating and incidence, number of onion thrips per plant, leaf color, glossiness, and axil openness ratings for Trial I entries measured several times throughout the 2009 and 2010 growing seasons at the Leyendecker Plant Science Research Center in Las Cruces, NM.

\begin{tabular}{|c|c|c|c|c|c|c|c|c|c|}
\hline \multirow[b]{3}{*}{ Entry $^{z}$} & \multicolumn{3}{|c|}{ IYS disease } & \multirow{2}{*}{\multicolumn{3}{|c|}{ Onion thrips (no./plant) ${ }^{\mathrm{w}}$}} & \multirow[b]{2}{*}{ Leaf color rating ${ }^{v}$} & \multirow{2}{*}{$\begin{array}{c}\text { Leaf waxiness } \\
\text { rating }^{\mathrm{u}}\end{array}$} & \multirow{2}{*}{$\begin{array}{l}\text { Leaf axil openness } \\
\text { rating }^{\mathrm{t}}\end{array}$} \\
\hline & Seve & $\operatorname{ating}^{y}$ & Incidence $(\%)^{x}$ & & & & & & \\
\hline & 16 & 20 & 16 & 12 & 16 & 20 & 16 & 16 & 16 \\
\hline \multicolumn{10}{|l|}{ Year } \\
\hline 2009 & 1.3 & 1.5 & 99.3 & 5.2 & 28.1 & 5.9 & 1.9 & 2.9 & 3.9 \\
\hline \multirow[t]{2}{*}{2010} & 1.0 & 2.5 & 90.1 & 17.3 & 16.3 & 17.4 & 1.4 & 2.1 & 3.8 \\
\hline & $* * *$ & $* * *$ & $* * *$ & $* * *$ & $* * *$ & *** & $* * *$ & $* * *$ & NS \\
\hline
\end{tabular}

${ }^{\mathrm{z}}$ Entries were tested in three replications. Plots were $3 \mathrm{~m}$ in length and consisted of two equally spaced rows sown per plot. Seeds were sown directly into the field on 23 Mar. 2009 and 23 Feb. 2010. 'T 433' is from American Takii (Salinas, CA), 'Advantage' and 'Harmony' are from Crookham Company (Parma, ID), 'Mesquite' and 'Tequila' are from DP Seeds (Yuma, AZ); 'Polar', 'Renegade', 'Rumba', and 'Vaquero' are from Nunhems USA (Palma, ID); 'Golden Spike' and 'Sterling' are from Monsanto Vegetable Seeds (Oxnard, CA); and all other entries are from New Mexico State University (Las Cruces, NM). NuMex Jose Fern. is an abbreviation for NuMex Jose Fernandez.

${ }^{\mathrm{y}}$ Ten plants per plot were rated individually for IYSV severity on a scale of 0 to 4 , where $0=$ no symptoms, $1=1$ to 2 small lesions per leaf, $2=>2$ medium-sized lesions per leaf, $3=$ lesions coalescing on more than $25 \%$ of the leaf, and $4=$ more than $50 \%$ leaf death

${ }^{x}$ Percentage of plants showing IYS disease symptoms were calculated based on 10 plants per plot.

${ }^{\mathrm{w}}$ The number of thrips (larvae and adults) per plant were counted from ten plants in the center of each plot.

${ }^{\mathrm{v}}$ Plots were rated for plant leaf color on a scale of 1 to 4 , where $1=$ light green, $2=$ dark green, $3=$ blue green, and $4=$ blue.

uPlots were rated for plant leaf waxiness on a scale of 1 to 4 , where $1=$ glossy, $2=$ semi glossy, $3=$ light wax, and $4=$ waxy.

${ }^{t}$ Plots were rated for plant leaf axil pattern on a scale of 1 to 4 , where $1=$ very open, $2=$ open, $3=$ slightly closed, and $4=$ tight.

NS, ${ }^{* * *},{ }^{* * *}$ Nonsignificant at $P>0.05$ or significant at $P \leq 0.05,0.01$, and 0.001 , respectively.

Table 2. Iris yellow spot (IYS) disease severity rating and incidence, number of onion thrips per plant, leaf color, waxiness, and axil openness ratings for Trial II entries measured several times throughout the 2010 and 2011 growing seasons at the Leyendecker Plant Science Research Center in Las Cruces, NM.

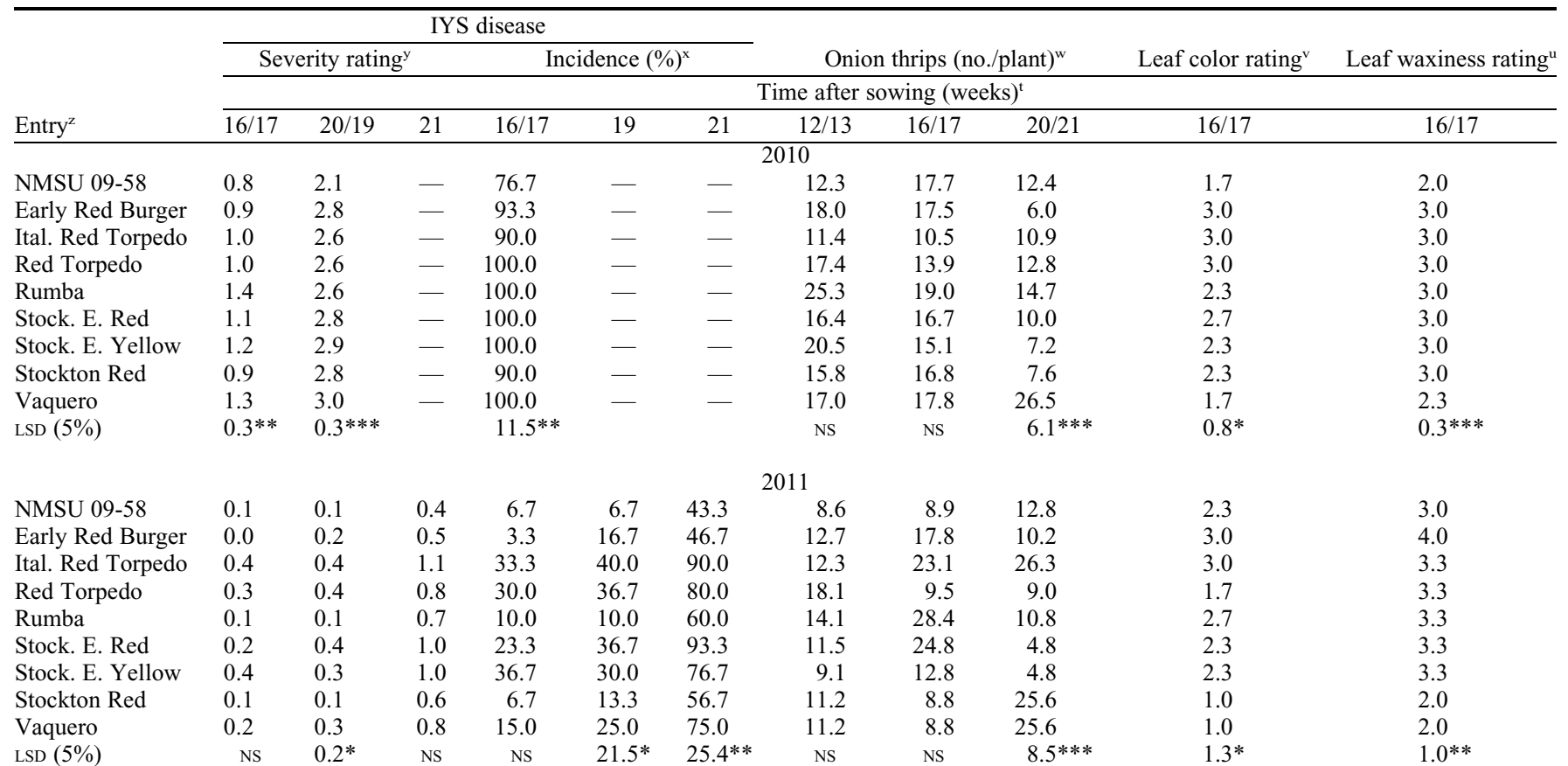

${ }^{\mathrm{z}}$ Entries were tested in three replications. Plots were $3 \mathrm{~m}$ in length and consisted two equally spaced rows sown per plot. Seeds were sown directly into the field on 23 Feb. 2010 and 2011. 'Early Red Burger', 'Ital. Red Torpedo' ('Italian Red Torpedo'), 'Red Torpedo', 'Stockton E. Red' ('Stockton Early Red'), 'Stock. E. Yellow' ('Stockton Early Yellow'), and 'Stockton Red' are from Lockhart Seeds, Inc. (Stockton, CA); NMSU 09-58 is from the NMSU breeding program (Las Cruces, NM); and 'Rumba' and 'Vaquero' are from Nunhems USA (Parma, ID).

${ }^{\mathrm{y}}$ Ten plants per plot were rated individually for IYS severity on a scale of 0 to 4 , where $0=$ no symptoms, $1=1$ to 2 small lesions per leaf, $2=>2$ medium-sized lesions per leaf, $3=$ lesions coalescing on more than $25 \%$ of the leaf, and $4=$ more than $50 \%$ leaf death.

${ }^{\mathrm{x}}$ Percentage of plants showing IYS disease symptoms were calculated based on 10 plants per plot.

${ }^{\mathrm{w}}$ The number of thrips (larvae and adults) per plant were counted from ten plants in the center of each plot.

${ }^{v}$ Plots were rated for plant leaf color on a scale of 1 to 4 , where $1=$ light green, $2=$ dark green, $3=$ blue green, and $4=$ blue.

uPlots were rated for plant leaf waxiness on a scale of 1 to 4 , where $1=$ glossy, $2=$ semi glossy, $3=$ light wax, and $4=$ waxy.

${ }^{\mathrm{t}}$ In 2011, Iris yellow spot (IYS) ratings were taken at 17, 19, and 21 weeks after transplanting; IYS disease incidence was calculated at 17, 19, and 21 weeks; thrips numbers were counted at 13,17, and 21 weeks; and leaf color and waxiness ratings were taken at 17 weeks.

NS, $*, * *, * * *$ Nonsignificant at $P>0.05$ or significant at $P \leq 0.05,0.01$, and 0.001 , respectively.

NMSU 09-58 (Table 2). Conversely, in 2011, when disease development was delayed and reduced as compared with 2010, 'Rumba' exhibited a low disease severity and incidence at 17 and 19 weeks (Table 2). In addition to 'Rumba', NMSU 09-58 and
'Stockton Red' also exhibited a lower disease severity and incidence at 19 weeks when compared with other entries (Table 2). This lack of disease symptom development in 2011 was not likely a result of poor thrips feeding as these entries possessed a comparable number of thrips per plant at 13 and 17 weeks as entries that exhibited greater disease severity (Table 2). Plants of 'Rumba' and NMSU 09-58 were rated as lighter in color than plants of 'Italian Red Torpedo' and 'Red Torpedo' that exhibited greater disease 
severity at 19 weeks. By 21 weeks, disease development progressed such that, disease severity was similar among all entries (Table 2). Even though there was no difference in disease severity, several entries exhibited lower disease incidence than other entries. NMSU 09-58 and 'Early Red Burger' had fewer plants with disease at 21 weeks than five other entries (Table 2).

At 20 weeks, plants of 'Advantage', 'Harmony', and NMSU 07-35-1 in Trial I exhibited less severe disease symptoms $(0.9$, 1.0 , and 1.0 , respectively) than plants of 10 other entries in 2009 (Table 1). When symptom expression was greater at the same period in 2010, plants of only 'Advantage' exhibited less disease (2.1) than plants of 16 other entries (Table 1). In both years, plants of these three entries exhibited a comparable number of thrips per plant at 16 weeks as plants of other entries that exhibited greater disease severity (Table 1). Any reduction of symptom severity was not likely caused by fewer thrips feeding on plants of 'Advantage', 'Harmony', and NMSU 07-35-1 (Table 1). The decrease in disease severity from 16 to 20 weeks in 2009 for plants of 'Advantage' and 'Harmony' (Table 1) could be attributed to different plants being rated in plots at each period since the same 10 plants per plot were not rated at each date. It would be ideal to rate the same plants at each of the rating time to prevent plant to plant variability between different ratings/rankings. In 2010, plants of NMSU 07-54-1 and NMSU 08-43 in Trial I exhibited fewer symptoms than plants of 24 other entries at 20 weeks (Table 1). When symptom development was less in 2009, these two entries were similar to other entries in the level of symptom expression. In both years, plants of NMSU 07-54-1 and NMSU 08-43 exhibited a comparable number of thrips per plant at 16 weeks as plants of other entries that exhibited greater disease severity (Table 1). Hence, reduced IYS symptom expressions were not probably be due to fewer thrips feeding on plants of NMSU 07-54-1 and NMSU 08-43.

In determining, if there were differences among entries for the number of thrips per plant, entries did not differ much at the earliest counting dates in 2009, 2010, and 2011 (Tables 1 and 2). At 16 weeks after seeding in 2009, 'Colorado no. 6' and NMSU 07-10-1 possessed fewer thrips per plant than 12 and 17 other entries, respectively (Table 1). These differences were not observed in 2010, probably because thrips numbers were generally lower at that period in that year. At 20 weeks in 2009 and 2010, plants of NMSU 07-10-1 in Trial I had fewer thrips than plants of 7 and 22 other entries, respectively (Table 1). At this time in the season, thrips appeared to find plants of this breeding line less attractive than other plants of adjacent entries. The reduced number of thrips per plant for NMSU 07-10-1 appeared to not be associated with a certain leaf color or amount of leaf wax. The leaf color rating of NMSU 07-10-1 ranged from 1.7 (2010) to 2.3 (2009), whereas the waxiness rating ranged from 2.7 (2010) to 3.3 (2009) (Table 1). These values were similar to values of other entries in which the number of thrips per plant at 20 weeks was greater than for NMSU 07-10-1. For example, leaf color ratings for 'Sterling' ranged from 1.3 (2010) to 2.0 (2009), whereas waxiness ratings ranged from 2.0 (2010) to 3.0 (2009) (Table 1). At 20 weeks in both years, plants of 'Sterling' possessed more thrips [8.3 (2009); 24.3 (2010)] than plants of NMSU 07-10-1 [0.4 (2009); 4.6 (2010)] (Table 1). Leaf color and waxiness may be more important factors in thrips feeding nonpreference earlier in the season when thrips are searching for onion plants to feed on. At 12 weeks, plants of NMSU 07-10-1 possessed a similar number of thrips per plant as plants of other entries (Table 1). Later in the growing season, other plant factors, such as, plant maturity, may be influencing thrips feeding preference for certain entries. Entries in both years matured at different times in a 3-4 week harvest period (data not shown).

In addition to NMSU 07-10-1, plants of NMSU 07-56-2 and 07-57-2 in Trial I exhibited fewer thrips than plants of 13 and 11 other entries, respectively, at 20 weeks after transplanting in 2010 (Table 1). These differences were not observed in 2009 , as most entries exhibited few thrips per plant at 20 weeks (Table 1). For those entries tested in Trial II during 2010 and 2011, plants of 'Stockton Early Yellow' and 'Stockton Red' possessed fewer thrips than plants of several other entries at 21 weeks after transplanting in both years (Table 2). At the same counting date, plants of 'Vaquero' possessed more thrips than plants of most entries in both years (Table 2).

As mentioned earlier, leaf color and amount of epicuticular wax are thought to influence thrips feeding preference with thrips preferring leaves with more epicuticular wax and a bluish color as opposed to less wax and lighter green color. Entries differed in their leaf color and amount of epicuticular leaf wax in both years; however, these differences did not seem to associate with differences in thrips number between entries early in the season when there were no differences among entries (Tables 1 and 2). For example, plants of 'Advantage' were rated as having leaves lighter green in color than plants of 'Rumba' in both 2009 and 2010 (Table 1). In both years, the number of thrips per plant was not different between these two entries. In addition, plants of NMSU 07-54-1 had less leaf wax than plants of 'Rumba' in both years; however, plants of both entries possessed a similar number of thrips $(\mathrm{Ta}-$ ble 1). In a 3-year study in New York, Nault and Huseth (2016) reported that the season total densities of onion thrips in plantings of 'Advantage' were similar to those in plantings of 'Santana' (a blue-green, waxy onion cultivar considered highly susceptible to thrips). However, thrips feeding damage was much greater in 'Santana' plantings than in 'Advantage' plantings, suggesting that either thrips fed less on 'Advantage' compared with 'Santana', or that the plant's response to thrips feeding was impacted much less in 'Advantage' than in 'Santana'.

There was no difference in the degree of leaf axil openness among the entries tested (Table 1). This plant character either may not be informative with regard to thrips feeding preference or the degree of openness did not vary enough among entries (i.e., only from 3.0 to 4.0 ) (Table 1) to make firm conclusions about its role in thrips resistance.

Entries, such as NMSU 07-10-1 that exhibited fewer number of thrips on its plants than most of the other entries later in the season in 2009 and 2010 (Table 1) and NMSU 09-58 that exhibited fewer IYS symptoms (Table 2) appeared promising as breeding lines. In both years, fewer plants of NMSU 09-58 exhibited disease symptoms early in the season compared with other entries (Table 2). In 2010, when disease symptoms were more severe than in 2011, fewer plants of NMSU 09-58 exhibited disease symptoms and symptoms tended to be less severe than on plants of other entries (Table 2). This difference was likely not due to a difference in thrips numbers between NMSU 09-58 and other entries. Early in the growing season, plants of NMSU 09-58 exhibited a comparable number of thrips as plants of other entries (Table 2). The plant foliage of NMSU 09-58 tended to be lighter green in color and have less wax than plants of other entries; however, these differences did not result in fewer thrips per plant. Since plant stress has been suggested as one of the determining factors in IYS disease expression (Cramer et al., 2014), NMSU 09-58 may be more tolerant of plant stress early in the growing season than other entries. NMSU 09-58 originated from 90 individual plants selected from four different intermediate-day breeding lines (that were progenitor lines for NMSU 07-33-1, 07-35-1, 07-52-1, and 0753-1) in 2008 for fewer and less severe IYS disease symptoms. Most of these lines have a similar genetic background as 'NuMex Jose Fernandez' (Corgan, 1994). The performance of NMSU 09-58 suggests that selection for reduced IYS symptom expression can be effective with continued efforts.

\section{Literature Cited}

Alimousavi, S.A., M.R. Hassandokht, and S. Moharramipour. 2007. Evaluation of Iranian onion germplasms for resistance to thrips. Intl. J. Agr. Biol. 9:897-900.

Bag, S., J. Singh, R.M. Davis, W. Chounet, and H.R. Pappu. 2009. Iris yellow spot virus in onion in Nevada and northern California. Plant Dis. 93:674.

Boateng, C.O., H.F. Schwartz, M.J. Havey, and K. Otto. 2014. Evaluation of onion germplasm for resistance to Iris yellow spot (Iris yellow spot virus) and onion thrips, Thrips tabaci. Southwestern Entomologist 39:237-260.

Corgan, J.N. 1994. 'NuMex Jose Fernandez' and 'NuMex Bolo' onion. N.M. Agric. Expt. Stn. Rel. Not.

Cramer, C.S., M. Mohseni-Moghadam, R.J. Creamer, and R.L. Steiner. 2012. Screening winter-sown entries for Iris yellow spot disease 
susceptibility, p. 80-99. In: S. Walker and C.S. Cramer (eds.). Proc. 2012 Natl. Allium Res. Conf. Las Cruces, NM.

Cramer, C.S., N. Singh, N. Kamal, and H.R. Pappu. 2014. Screening onion plant introduction accessions for tolerance to onion thrips and Iris yellow spot. HortScience 49:1253-1261.

Creamer, R., S. Sanogo, A. Moya, J. Romero, R. Molina-Bravo, and C. Cramer. 2004. Iris yellow spot virus on onion in New Mexico. Plant Dis. 88:1049.

Crowe, F.J. and H.R. Pappu. 2005. Outbreak of Iris yellow spot virus in onion seed crops in central Oregon. Plant Dis. 89:105.

Damon, S.J., R.L. Groves, and M.J. Havey. 2014. Variation for epicuticular waxes on onion foliage and impacts on numbers of onion thrips. J. Amer. Soc. Amer. Sci. 139:495-501.

Diaz-Montano, J., J. Fail, M. Deutschlander, B.A. Nault, and A.M. Shelton. 2012a. Characterization of resistance, evaluation of the attractiveness of plant odors, and effect of leaf color on different onion cultivars to onion thrips (Thysanoptera: Thripidae). J. Econ. Entomol. 105:632-641.

Diaz-Montano, J., M. Fuchs, B.A. Nault, and A.M. Shelton. 2012b. Resistance to onion thrips (Thysanoptera: Thripidae) in onion cultivars does not prevent infection by Iris yellow spot virus following vector-mediated transmission. Fla. Entomol. 95:156-161.

du Toit, L.J., H.R. Pappu, K.L. Druffel, and G.Q. Pelter. 2004a. Iris yellow spot virus in onion bulb and seed crops in Washington state. Plant Dis. 88:222.

du Toit, L.J., G.Q. Pelter, and H.R. Pappu. 2004b. IYSV challenges to the onion seed industry in Washington, p. 213-217. In: C. Swift (ed.). Proc. 2004 Natl. Allium Res. Conf., Grand Junction, CO.

Gent, D.H., L.J. du Toit, S.F. Fichtner, S.K. Mohan, H.R. Pappu, and H.F. Schwartz. 2006. Iris yellow spot virus: An emerging threat to onion bulb and seed production. Plant Dis. 90:1468-1480.

Gent, D.H., H.F. Schwartz, and R. Khosla. 2004. Distribution and incidence of Iris yellow spot virus in Colorado and its relation to onion plant population and yield. Plant Dis. 88:446-452.
Gill, H.K., H. Garg, A.K. Gill, J.L. Gillett-Kaufman, and B.A. Nault. 2015. Onion thrips (Thysanoptera: Thripidae) biology, ecology, and management in onion production systems. J. Integ. Pest Mgt. 6:6.

Hall, J.M., S.K. Mohan, E.A. Knott, and J.W. Moyer. 1993. Tospoviruses associated with scape blight of onion (Allium cepa) seed crops in Idaho. Plant Dis. 77:952.

Hoepting, C.A., H.F. Schwartz, and H.R. Pappu. 2007. First report of Iris yellow spot virus on onion in New York. Plant Dis. 91:327.

Jones, H.A., S.F. Bailey, and S.L. Emsweller. 1934. Thrips resistance in onion. Hilgardia 8:215-252.

Kritzman, A., M. Lampel, B. Raccah, and A. Gera. 2001. Distribution and transmission of Iris yellow spot virus. Plant Dis. 85:838-842.

MacIntyre Allen, J.K., C.D. Scott-Dupree, J.H. Tolman, and C.R. Harris. 2005. Resistance to Thrips tabaci to pyrethroid and organophosphorus insecticides in Ontario, Canada. Pest Mgt. Sci. 61:809-815.

Martin, N.A., P.J. Workman, and R.C. Butler. 2003. Insecticide resistance in onion thrips (Thrips tabaci) (Thysanoptera: Thripidae). N. Z. J. Crop Hort. Sci. 31:99-106.

Miller, M.E., R.R. Saldana, M.C. Black, and H.R. Pappu. 2006. First report of Iris yellow spot virus on onion (Allium cepa) in Texas. Plant Dis. 90:1359.

Mohseni-Moghadam, M., C.S. Cramer, R.L. Steiner, and R. Creamer. 2011. Evaluating winter-sown onion entries for Iris yellow spot virus susceptibility. HortScience 46:1224-1229.

Molenaar, N. 1984. Genetics, thrips (Thrips tabaci L.) resistance and epicuticular wax characteristics of nonglossy and glossy onions (Allium cepa L.) Univ. of Wisconsin, Madison, Wisc, Ph.D. Diss.

Mote, U.N. and H.N. Sonone. 1977. Relative susceptibility of different varieties of onion (Allium cepa) to thrips (Thrips tabaci Lind.). J. Maharashtra Agr. Univ. 2:152-155.

Mullis, S.W., D.B. Langston, Jr., R.D. Gitaitis, J.L. Sherwood, A.C. Csinos, D.G. Riley, A.N. Sparks, R.L. Torrance, and M.J. Cook. 2004. First report of Vidalia onion (Allium cepa) naturally infected with Tomato spotted wilt virus and Iris yellow spot virus (Family
Bunyaviridae, Genus Tospovirus) in Georgia. Plant Dis. 88:1285.

Multani, P.S., C.S. Cramer, R.L. Steiner, and R. Creamer. 2009. Screening winter-sown onion entries for Iris yellow spot virus tolerance. HortScience 44:627-632.

Nagata, T., A.C.L. Almeida, R. de O. Resende, and A.C. de Avila. 1999. The identification of the vector species of iris yellow spot tospovirus occurring on onion in Brazil. Plant Dis. 83:399.

Nault, B.A. and A.S. Huseth. 2016. Evaluating an action-threshold based insecticide program on onion cultivars varying in resistance to onion thrips (Thysanoptera: Thripidae). J. Econ. Entomol. 109:1772-1778.

Pappu, H. and M. Matheron. 2008. Characterization of Iris yellow spot virus from onion in Arizona. Plant Health Prog., doi: 10.1094/PHP2008-0711-01-BR.

Pawar, B.B., A.V. Patil, and H.N. Sonone. 1975. A thrips resistant glossy selection in white onions. Res. J. Mahatma Phule Agr. Univ. 6:152-153.

Poole, G.J., H.R. Pappu, R.M. Davis, and T.A. Turini. 2007. Increasing outbreaks and impact of Iris yellow spot virus in bulb and seed onion crops in the Imperial and Antelope Valleys of California. Plant Health Prog., doi: 10.1094/ PHP-2007-0508-01-BR.

Schwartz, H.F., W.M. Brown, Jr., T. Blunt, and D.H. Gent. 2002. Iris yellow spot virus on onion in Colorado. Plant Dis. 86:560.

Schwartz, H.F., D.H. Gent, S.F. Fichtner, R.W. Hammon, and R. Khosla. 2005. Integrated management of Iris yellow spot virus in onion, p. 207-212. In: C. Swift (ed.). Proc. 2004 Natl. Allium Res. Conf., Grand Junction, CO.

Shelton, A.M., B.A. Nault, J. Plate, and J.Z. Zhao. 2003. Regional and temporal variation in susceptibility to $\lambda$-cyhalothrin in onion thrips, Thrips tabaci (Thysanoptera: Thripidae), in onion fields in New York. J. Econ. Entomol. 96:1843-1848.

Shock, C.C., E.B.G. Feibert, L.B. Jensen, S.K. Mohan, and L.D. Saunders. 2008. Onion variety response to Iris yellow spot virus. HortTechnology 18:539-544.

Walker, S., J. Ashigh, C.S. Cramer, T. Sammis, and B. Lewis. 2009. Bulb onion culture and management for southern New Mexico. New Mexico Coop. Ext. Serv. Circ. 563. 